\title{
A DINÂMICA DO MODELO DOS CAMPOS SEMÂNTICOS NA CONSTRUÇÃO DOS NÚMEROS REAIS
}

\author{
A DYNAMIC MODEL OF SEMANTIC FIELDS IN CONSTRUCTION OF REAL NUMBERS
}

\author{
Mariana dos Santos Cezar, Rodolfo Chaves
}

Instituto Federal do Espírito Santo

E-mail: marianascezar@hotmail.com, rodolfochaves20@gmail.com

\section{Resumo}

Tratamos neste artigo da produção de significados matemáticos nos processos de ensino e de aprendizagem da construção dos números reais. De cunho qualitativo, nos moldes da pesquisa-ação, desenvolvemos reflexões, discussões e intervenções, entre pesquisadores e sujeitos da pesquisa. Propomos reflexões a respeito de paradigmas que permeiam o ensino da construção dos números reais. Para tal, participaram 32 alunos da Licenciatura em Matemática de uma Instituição Pública, durante um período de três meses. Como aporte teórico, adotamos o Modelo dos Campos Semânticos. A investigação permitiu entender que a visão que temos enquanto professores, pode não ser a mesma que nossos alunos possuem, que os significados que produzimos para uma situação-problema variam de acordo com os sujeitos.

Palavras-chave: números reais. formação de professores de matemática. modelo dos campos semânticos. produção de significado.

\begin{abstract}
We treat this article the production of mathematical meanings in the teaching and learning of the construction of the real numbers. Of qualitative nature, along the lines of action research, develop reflections, discussions and activities between researchers and research subjects. We propose reflections on paradigms that underlie the teaching of construction of real numbers. To do this, participated 32 students of the degree in Mathematics of a public institution for a period of three months. As a theoretical framework we adopted the model of Semantic Fields. The investigation has to understand that the vision we have as teachers, can not be the same as our students have, that the meanings we produce to a problem situation vary according to the subject.
\end{abstract}

Keywords: real numbers. mathematics teachers training. model of semantic fields. production meaning. 


\section{INTRODUÇÃO}

Como professores de Matemática atuamos na Educação Básica, no Ensino Superior e em formações (inicial e continuada) de professores e nos deparamos com incoerências e circularidades em relação ao ensino de números reais. Advindas de alunos e professores de Matemática, muitas dúvidas têm emergido quanto à definição dos números, segundo a classificação dos conjuntos numéricos aos quais pertencem. Comprovamos tal problemática em encontros de formação continuada de professores de Matemática, que destacaram a dificuldade de adaptar as definições que estudamos ao longo de nossa formação inicial como professores. Diante dessa experiência nos propomos a pesquisar sobre o tema e refletir sobre a formação do professor de Matemática.

Com o objetivo de analisarmos que significados matemáticos são produzidos, por meio dos processos de ensino e de aprendizagem da construção dos números reais até uma compreensão e possíveis definições de números racionais, irracionais e reais, nos propusemos a desenvolver a construção dos números reais com alunos da Licenciatura em Matemática. A investigação se deu numa sala de aula de alunos do 1o período e com um grupo de alunos concluintes que cursavam disciplinas finalistas, estudantes de uma Instituição Pública Brasileira. Para tal, nos embasamos no Modelo dos Campos Semânticos (MCS) no que diz respeito à produção de significado.

Com o intuito de desenvolver a pesquisa com o envolvimento dos sujeitos e dos pesquisadores, de forma participativa, de maneira que as fases da pesquisa pudessem ser construídas coletivamente, buscamos um método que subsidiasse essa proposta. Assim, adotamos a pesquisa-ação.

Para a construção dos números inserimos um pouco da História da Matemática, destacamos alguns aspectos históricos sobre a evolução dos números reais e a formulação de sua definição. Para tal, descrevemos o problema da medida que ocasionou na construção do campo racional; o surgimento de segmentos incomensuráveis que proporcionaram uma 
extensão do campo racional para o campo irracional; os cortes de Richard Dedekind, que segundo Caraça (1989), provê uma fundamentação mais rigorosa à definição de números reais. Destacamos também a importância de se utilizar esses procedimentos na formação de professores de Matemática (inicial e continuada), visando uma melhor compreensão dos porquês de tais definições. Por fim, analisamos se houve alguma mudança em relação aos significados matemáticos produzidos, observados antes das construções e após tais construções.

\section{FUNDAMENTAÇÃO TEÓRICA}

Neste estudo adotamos um modelo epistemológico de conhecimento que nos possibilitou analisar com mais propriedade o processo de produção de significado. Como referencial teórico o Modelo dos Campos Semânticos foi concebido por Rômulo Campos Lins. Com o intuito de delinearmos nossas perspectivas, descrevemos alguns conceitos do MCS e suas relações essenciais para esta pesquisa.

Lins (2012) movido por suas inquietações relacionadas à sala de aula "[...] queria dar conta de caracterizar o que os alunos estavam pensando quando 'erravam', mas sem recorrer a esta ideia de erro" (LINS, 2012, p.11). Nesta perspectiva, direciona seu olhar na busca da produção de significado; isto é, o que os alunos pensam e falam quando resolvem algum problema, seja "certo" ou "errado"; qual a justificativa para esta resolução. Questionar nossas verdades nos permite essa produção, e essa produção de significado nos conduz a produção do conhecimento. Segundo Lins (2012) a maneira como produzidos um conhecimento está relacionada à forma como compreendemos uma enunciação. Mas, em que consiste o conhecimento? Lins (2012) defende que um conhecimento consiste de uma crença-afirmação, junto com uma justificação. O sujeito acredita em algo (crença) que se caracteriza com uma afirmação que justifica sua crença-afirmação, e juntos (crençaafirmação e justificação) produzem, segundo o referencial supracitado, o conhecimento. 
Lins (2012) destaca ainda que nenhum conhecimento vem ao mundo ingenuamente. "Aquele que o produz, que o enuncia, já fala em uma direção (o interlocutor) na qual o que ele diz, e com a justificação que tem, pode ser dito" (LINS, 2012, p.13). Falamos na direção de um interlocutor e esperamos que o mesmo aceite e reproduza o que dizemos, utilizando a justificação que acreditamos.

Nesse contexto podemos pensar que várias pessoas podem ler o mesmo texto e produzir ou não diferentes significados. Por exemplo, na afirmação "número irracional é todo número que não é racional", muitos tomam como universo o conjunto dos números reais e justificam compreender que, no domínio dos reais, o número não racional é irracional. Por outro lado, alguém pode questionar se a $V$-1 (não racional) é um número irracional, pois pela afirmação, "irracional é todo número que não é racional". Neste caso, não estaria considerando apenas o domínio dos reais, visto que, não foi estabelecido isso na afirmação. No exemplo descrito, os sujeitos atribuíram diferentes significados ou até mesmo produziram diferentes conhecimentos, isso se dá pela produção de significado.

Quando produzimos significados e emitimos enunciações estabelecemos uma relação que a nosso olhar, e no contexto ao qual estão inseridas, se constitui como verdadeira. Mas, existe uma diferença quando falamos em verdades. No MCS, a verdade é atribuída ao conhecimento produzido, e o fato de ter sido enunciado na direção de um interlocutor se torna verdadeiro, contudo, isso não autoriza dizer que o que é afirmado seja verdade, no sentido de verdade "universal".

Em tal contexto, Lins (1999) esclarece o fato de o sujeito dizer algo é a garantia de poder dizer. Pensamos nessa situação tomando como exemplo os números irracionais, como já descritos. Se falarmos que "número irracional é todo número que não é racional", para sujeitos que nem sequer pensam na existência de raízes de números negativos, essa afirmação é verdadeira, portanto, legítima. No entanto, se falarmos para sujeitos que produzem tal conhecimento, a palavra "todo" pode gerar conflitos, como já destacado. 
Neste ponto de vista, "o aspecto central de toda aprendizagem - em verdade o aspecto central de toda a cognição humana - é a produção de significado" (LINS, 1999, p.86).

significado é o conjunto de coisas que se diz a respeito de um objeto. Não o conjunto do que se poderia dizer, e, sim, o que efetivamente se diz no interior de uma atividade. Produzir significado é, então, falar a respeito de um objeto (LINS e GIMENEZ, 1997, p.145-146).

Logo, o MCS admite uma perspectiva diferente, a de que o conhecimento produzido pelo aluno pode não ser o mesmo produzido e enunciado pelo professor; no entanto, ambos são considerados válidos.

No processo de produção de significado é estabelecido um espaço comunicativo ou espaços comunicativos, tomado(s) como processo(s) de interação onde os interlocutores são compartilhados. A enunciação é produzida pelo o autor que fala na direção de um leitor, constituído pelo o autor. Por sua vez, o leitor produz significado para a enunciação e fala na direção de um autor, constituído pelo o leitor. De acordo com esta perspectiva, durante todo o processo de comunicação são relacionados três elementos fundamentais: autor, texto e leitor. Nesse sentido, Silva (2003, p.62) enfatiza:

O autor é aquele que, no processo, produz a enunciação: um professor em uma aula expositivo-explicativa, um artista plástico expondo seus trabalhos ou um escritor apresentando sua obra. O leitor é aquele que, no processo, se propõe a produzir significados para o resíduo das enunciações como, por exemplo, o aluno que, assistindo à aula, busca entender o que o professor diz, o crítico de arte ou o leitor do livro. Já o texto, é entendido como qualquer resíduo de enunciação para o qual o leitor produza algum significado.

Nesse processo, 
o que faz do texto o que ele é, é a crença do leitor que ele é, de fato, resíduo de uma enunciação, ou seja, um texto é delimitado pelo leitor; além disso, ele é sempre delimitado no contexto de uma demanda de que algum significado seja produzido para ele (LINS, 1997, p.59).

No mesmo viés, nas prerrogativas do espaço comunicativo descrito por Lins dentro do MCS, é que Chaves (2004, p.12) enfatiza:

que nossos entendimentos das leituras que realizamos se processam de forma que os autores chegam até nós (o leitor) como resíduos de enunciações, que se constitui em texto a partir de nossa produção de significados, que novamente resulta em resíduo de enunciação.

Assim, pensamos que, quando entendemos uma enunciação (não necessariamente da mesma forma que o autor propôs, mas em nossa perspectiva, de acordo com nossa compreensão), estamos produzindo significados e, ao enunciá-los, novos leitores produzirão significados que poderão estar de acordo ou não com o nosso.

Em síntese, nesta pesquisa somos autores e leitores, os sujeitos da pesquisa são autores e leitores. Na medida em que construímos os campos numéricos, como autores, os sujeitos são os leitores, como participantes desta construção; os leitores se tornam autores e nós nos tornamos leitores, e na medida em que mostramos os resultados de nossas reflexões acerca dos significados matemáticos que os sujeitos produziram, nós nos tornamos leitores e autores, e assim segue o processo, como se estivéssemos em um ciclo; ora autores, ora leitores. 


\section{FUNDAMENTOS METODOLÓGICOS}

A pesquisa é caracterizada com uma abordagem qualitativa, nos moldes da pesquisa-ação segundo Barbier (2012), Thiollent (2011). Essa opção metodológica se deu devido ao nosso intuito de investigar o processo de produção de significado por meio das enunciações dos sujeitos.

A pesquisa de campo foi desenvolvida com alunos da Licenciatura em Matemática de uma Instituição Pública Brasileira, sendo uma turma do 10 período (iniciantes) e um grupo de alunos concluintes, onde desenvolvemos o estudo da construção dos números reais tendo como referencial Caraça (1989). O processo de desenvolvimento e investigação da pesquisa foi dividido em 5 etapas: i) no primeiro encontro explicamos os procedimentos da pesquisa. O tema, o porquê da escolha, os objetivos a serem alcançados e a importância da participação dos grupos de alunos. Convidamo-los a participar da pesquisa e solicitamos suas respectivas autorizações; ii) no segundo encontro iniciamos as construções. Trabalhamos com questionários e gravações de áudio e juntos construímos o campo racional; iii) no terceiro encontro construímos o campo irracional; iv) no quarto encontro construímos o campo real; v) no quinto encontro realizamos uma plenária, análise aos resultados.

O processo de investigação partiu de uma conversa com os sujeitos acerca do tema em questão e do conhecimento prévio em relação às definições de números reais, mais especificamente, dos racionais e irracionais. Após este primeiro momento iniciamos o estudo da construção do campo racional onde foi questionado aos sujeitos como eles definiam números racionais antes e depois da construção com o intuito de realizarmos uma analogia em suas respostas no término do processo.

De modo análogo iniciamos a construção do campo irracional com a questão: defina um número irracional. Após a construção do campo irracional propomos aos sujeitos que definissem novamente os números irracionais. Tal solicitação gerou muitas reflexões acerca da existência de uma definição para tal campo numérico, reflexões estas que serão descritas 
mais adiante.

Por fim, sobre a construção dos campos numéricos, propomos que os sujeitos definissem números reais. Nessa perspectiva todo o processo de construção dos campos racional e irracional seria necessário para se compreender porque "união dos racionais com os irracionais". No final da construção do campo racional, propomos novamente aos sujeitos que definissem números reais.

Finalizamos o processo de investigação com a plenária que foi um momento de reflexão, discussão e de apresentação (por meio de slides) das análises prévias do material registrado. Nesse momento os sujeitos puderam também fazer suas análises acerca do que foi desenvolvido e registrado ao longo da pesquisa.

\section{INVESTIGAÇÕES A RESPEITO DA ANÁLISE DE DADOS}

Para a investigação à análise dos dados pontuamos e descrevemos as enunciações dos sujeitos registradas por meio de questionários e gravações em áudio. Em nossa análise consideramos que, quando uma pessoa produz significados para um resíduo de enunciação (no caso, as enunciações dos pesquisadores, colegas de turma e a escrita do livro) nos propomos a refletir sobre o que aquelas enunciações nos têm a dizer sobre o processo de construção dos números reais desenvolvido. Ou seja, que objetos foram constituídos no interior de uma atividade? O que foi possível perceber da produção de conhecimento fazendo uma analogia com o antes e o depois? Dessa forma, descrevemos alguns significados que foram produzidos aos resíduos de enunciações dos sujeitos envolvidos. Como a pesquisa foi desenvolvida com 32 sujeitos fica inviável descrever toda a análise, logo destacaremos apenas alguns registros, mas que nos proporcionarão compreendermos o processo.

Optamos por nos focar no antes e depois de cada construção de campo numérico, lembrando que durante todo o processo de produção os sujeitos foram envolvidos por meio 
de situações-problemas.

Na construção do campo racional sobre a questão defina números racionais, evidenciamos como respostas:

Antes

Sujeito 1: "Número racional que pode ser representado por uma razão (ou fração) entre dois números inteiros."

Sujeito 2: "É o número que consigo extrair uma raiz e como resultado tenho um número inteiro. Ex: v9 = \pm 3 ou fracionário (periódico)."

Depois

Sujeito 1: "É a divisão entre dois números inteiros, ou seja, a razão entre dois números inteiros, sendo que o denominador nunca seja zero."

Observamos que essa resposta ficou mais fundamentada após a construção e algumas restrições foram evidenciadas, como por exemplo, o denominador ser diferente de zero.

Sujeito 2: "São todos os números que são representados na forma $A / B$, onde $A$ e $B$ são números inteiros e sendo $B \neq 0$."

Observamos que essa resposta, comparada com a primeira, evidenciou a produção de conhecimento no que diz respeito à formulação para expressar um número racional.

Durante a construção desse campo outras reflexões foram realizadas de forma a propiciar o envolvimento dos sujeitos nesse processo.

Em relação à definição dos números irracionais destacamos algumas respostas, são elas:

Antes

Sujeito 1: "Número irracional é um número que representa uma grandeza 
incomensurável, pois com os conjuntos até então criados não é possível expressar a medida desses segmentos."

Sujeito 2: "Número irracional é um número que não pode ser escrito como uma fração irredutível, pois seu resultado não é um número inteiro e nem uma fração irredutível."

Depois

Sujeito 1: "São números que não podem ser escritos na forma $a / b$ com a e b inteiros e $b \neq 0$. Porque não há como mensurar ' $a$ ' tomando ' $b$ ' como unidade."

Observamos nessa resposta que o sujeito relaciona a ideia de números irracionais com medidas e unidades de medidas. Isso demonstra que o sujeito construiu conhecimento acerca de segmentos incomensuráveis, ou seja, constituiu um pensamento geométrico, o que complementa seu raciocínio inicial. Além disso, demonstra que construiu o pensamento algébrico acerca da definição de números racionais.

Sujeito 2: "Número irracional é todo número que não pode ser escrito na forma $\mathrm{m} / \mathrm{n}$, onde $\mathrm{n} \neq 0$ e não pertence a nenhum campo numérico já definido (N, Z e Q)."

Observamos que o sujeito, inicialmente, descreve número irracional como aquele que não possui o formato dos racionais. Após a construção do campo irracional ele descreve a mesma ideia, porém relacionando isso com a definição que construímos para os números racionais. Com isso, temos a percepção de que o sujeito construiu um pensamento mais algébrico.

No final da construção os sujeitos foram ouvidos e relataram que o processo de construção dos números irracionais proporcionou a produção do conhecimento, pois permitiu compreender a necessidade de sua constituição para a resolução de problemas cotidianos, bem como, entender o processo de extensão numérica. Além disso, evidenciamos a não existência de uma definição para caracterizar ou generalizar o "formato" de um número 
irracional, assim como para os racionais.

Por fim, construímos o campo dos números reais. Solicitamos antes de iniciarmos a construção, que os sujeitos definissem um número real. Algumas respostas:

\section{Antes}

Sujeito 1: "É todo número pertencente ao conjunto dos reais, que são todos os números, com exceção dos complexos."

Sujeito 2: "É a união dos conjuntos naturais, inteiros, racionais e irracionais. Porque com a união desses conjuntos temos a propriedade da continuidade."

Depois

Sujeito 1: "É a união dos conjuntos racional e irracional."

Observamos que o sujeito reafirmou seu conhecimento inicial, destacando uma definição que remete a já utilizada por ele.

Sujeito 2: "É a união dos conjuntos racionais e irracionais, porque necessitam de uma expansão do campo racional."

Observamos que o sujeito relaciona a definição de número real com a necessidade de expandir o campo racional. Isso foi observado durante a construção do campo real. Em relação à resposta inicial, o sujeito observa, na resposta após construção, que não há necessidade de descrever também a união dos naturais e dos inteiros, pois estes já fazem parte do conjunto dos racionais, com isso, observamos que o sujeito produziu significados.

No final do processo de pesquisa perguntamos aos sujeitos o que eles observaram sobre tal construção e os sujeitos evidenciaram a importância do processo para a produção do conhecimento acerca da definição de número real, e alguns sujeitos acharam o processo abstrato ou não muito utilizado no Ensino Fundamental. 


\section{CONIDERAÇÕES FINAIS}

No intuito de direcionarmos essa pesquisa por meio de construções, intervenções, reflexões e questionamentos buscamos ir além do que uma simples investigação ou análise de resultados, visamos acima de tudo a produção de significados matemáticos.

Durante o processo de análise dos resultados, constatamos que refletir a respeito dos significados produzidos por diversos sujeitos não constitui uma tarefa fácil, uma vez que, os significados produzidos pelos leitores, a partir de suas respectivas enunciações, podem não ser os mesmos emitidos pelos respectivos autores destas enunciações. Dessa forma, o trabalho com o MCS representou um diferencial: passamos a prestar mais atenção no que os sujeitos enunciam e a refletir a respeito dos significados que eles produzem nos processos de ensino e de aprendizagem. Aprendemos que a sala de aula precisa ser um espaço comunicativo, onde é fundamental que o professor "leia" o aluno e compreenda que é a partir de suas enunciações e das enunciações dos alunos que a relação dialógica de comunicação é estabelecida.

Sobre a construção dos números evidenciamos que o processo de construção do campo racional proporcionou compreendermos que, o que consideramos como definição de números racionais: "Todo número racional pode ser escrito na forma $\mathrm{m} / \mathrm{n}$, com $\mathrm{m}$ e $n$ inteiros e $n \neq 0^{\prime \prime}$, é uma generalização algébrica que permite representar qualquer número pertencente a este conjunto. Em contrapartida, a construção do campo irracional proporcionou compreendermos que, não existe uma generalização algébrica que permita expressar o formato de um número irracional. Com isso chegamos, junto com os sujeitos da pesquisa, à conclusão de que para os números irracionais não existe uma única definição.

O processo de construção do campo real proporcionou entendermos o porquê da clássica afirmação "União dos racionais com os irracionais". Compreendemos a partir dos cortes de Dedekind - descrito na obra de Caraça (1989) - a ideia de união desses conjuntos e, 
necessariamente que, o corte na reta real que não constituiu um número racional é um número irracional. Tal façanha possibilitou à produção de conhecimento acerca da definição de números reais. Isso foi constatado por meio das enunciações emitidas pelos sujeitos que descreveram a importância da construção dos números para a formação do professor de Matemática.

Por fim, destacamos que a importância dessa pesquisa está pautada no que ela representa para nós participantes e para a formação do professor de Matemática. Entendemos que o processo de construção dos números reais representa mais do que a compreensão de um método. Concebe o alicerce para a produção de conhecimento do professor de Matemática. Além disso, a pesquisa proporciona mais uma etapa em busca da compreensão do processo de produção de significado desenvolvido por nossos alunos, para que possamos com mais propriedade compreender esse processo e por meio dele intervir nos processos de ensino e de aprendizagem.

\section{REFERÊNCIAS}

BARBIER, René. A Pesquisa-Ação. Tradução Lucie Didio. Nova Edição. Brasília: Liber Livro Editora, 2012.

CARAÇA, Bento de Jesus. Conceitos fundamentais da Matemática. 9. ed. Lisboa: Livraria Sá da Costa Editora, 1989.

CEZAR, Mariana dos Santos. A Produção de Significados Matemáticos na Construção dos Números Reais. Dissertação (Mestrado em Educação em Ciências e Matemática). Programa de Pós-Graduação em Educação em Ciências e Matemática, Instituto Federal do Espírito Santo. Vitória, 2014.

CHAVES, Rodolfo. Por que anarquizar o ensino de Matemática intervindo em questões socioambientais? Tese (Doutorado em Educação Matemática). Programa de Pós-Graduação em Educação Matemática, Instituto de Geociências e Ciências Exatas de Rio Claro. Universidade Estadual Paulista, 2004.

LINS, Romulo Campos. O modelo teórico dos campos semânticos: uma análise 
epistemológica da álgebra e do pensamento algébrico. Revista Dynamis Blumenau, v. 1, n. 7, FURB, p. 29-39, abr/jun 1994.

; GIMENEZ, Joaquim. Perspectivas em aritmética e álgebra para o século XXI. 3. ed. Campinas: Papirus, 1997.

Por que discutir teoria do conhecimento é relevante para a Educação Matemática. Em: Bicudo, Maria Aparecida Viggiani (Org). Pesquisa em Educação Matemática: concepções e perspectivas. São Paulo: Editora da UNESP, p. 75-94, 1999.

. O modelo dos campos semânticos: estabelecimentos e notas de teorizações. Em: ANGELO, Claudia Laus. (Org). Modelo dos Campos Semânticos e Educação Matemática: 20 anos de história. São Paulo: Midiograf, p. 11-30, 2012.

SILVA, Amarildo Melchiades. Sobre a Dinâmica da Produção de Significados para a Matemática. Tese (Doutorado em Educação Matemática). Instituto de Geociências e Ciências Exatas, Universidade Estadual Paulista. Rio Claro, 2003.

THIOLLENT, Michael. Metodologia da pesquisa-ação. 18. ed. São Paulo: Cortez, 2011. 